\title{
Endotoxin, ergosterol, muramic acid and fungal DNA in dust from schools in Johor Bahru, Malaysia - associations with rhinitis and sick building syndrome (SBS) in junior high school students
}

\begin{abstract}
This paper studied associations between ocular symptoms, rhinitis, throat and dermal symptoms, headache and fatigue in students by ethnicity and in relation to exposure to chemical microbial markers and fungal DNA in vacuumed dust in schools in Malaysia. A total of 462 students from 8 randomly selected secondary schools in Johor Bahru, Malaysia, participated (96\% response rate). Dust was vacuumed from 32 classrooms and analysed for levels of five types of endotoxin as 3-hydroxy fatty acids (C10, C12, C14, C16 and C18 3$\mathrm{OH})$, muramic acid, ergosterol and five sequences of fungal DNA. Multiple logistic regression was applied. Totally $11.9 \%$ reported weekly ocular symptoms, $18.8 \%$ rhinitis, $15.6 \%$ throat and $11.1 \%$ dermal symptoms, $20.6 \%$ headache and $22.1 \%$ tiredness. Totally $21.1 \%$ reported pollen or furry pet allergy (atopy) and $22.0 \%$ parental asthma or allergy. Chinese students had less headache than Malay and Indian had less rhinitis and less tiredness than Malay. Parental asthma/allergy was a risk factor for ocular (odds ratio $=3.79$ ) and rhinitis symptoms $(\mathrm{OR}=3.48)$. Atopy was a risk factor for throat symptoms $(\mathrm{OR}=2.66)$, headache $(\mathrm{OR}=2.13)$ and tiredness $(\mathrm{OR}=2.02)$. There were positive associations between amount of fine dust in the dust samples and ocular symptoms $(\mathrm{p}<0.001)$ and rhinitis $(\mathrm{p}=$ 0.006). There were positive associations between $\mathrm{C} 143-\mathrm{OH}$ and rhinitis $(\mathrm{p}<0.001)$ and between $\mathrm{C} 183-\mathrm{OH}$ and dermal symptoms $(\mathrm{p}=0.007)$. There were negative (protective) associations between levels of total endotoxin (LPS) $(\mathrm{p}=0.004)$ and levels of ergosterol $(\mathrm{p}=$ 0.03 ) and rhinitis and between $\mathrm{C} 123-\mathrm{OH}$ and throat symptoms $(\mathrm{p}=0.004)$. In conclusion, the amount of fine dust in the classroom was associated with rhinitis and other SBS symptoms and improved cleaning of the schools is important. Endotoxin in the school dust seems to be mainly protective for rhinitis and throat symptoms but different types of endotoxin could have different effects. The ethnic differences in symptoms among the students deserve further attention.
\end{abstract}

Keyword: Endotoxin; Microbial markers; Indoor environment; Sick building syndrome (SBS); Rhinitis; School students; Fungal DNA; Malaysia 